\title{
Editorial Note: IoT Technology for Promoting Multimedia Services
}

\author{
Published online: 4 February 2019 \\ (C) Springer Science+Business Media, LLC, part of Springer Nature 2019
}

Multimedia Tools and Applications gratefully acknowledges the editorial work of the scholars listed below on the special issue entitled, "IoT Technology for Promoting Multimedia Services."

Of 43 papers submitted to this issue, 26 were eventually accepted after a stringent peer-review process.

\section{Joeseph Sok-Pal Cho (Corresponding Guest Editor)}

Korea Institute of Science and Technology Information (KISTI), Korea joesephsokpalcho@gmail.com

\section{Gernot Dreisiebner}

University of Graz, Austria

gernot.dreisiebner@uni-graz.at

\section{Olha Hrynkevych}

Lviv National Ivan Franco University, Ukraine

ogrynkevych@gmail.com

\section{Harksoo Kim}

Kangwon National University, Korea

nlpdrkim@kangwon.ac.kr

Publisher's Note Springer Nature remains neutral with regard to jurisdictional claims in published maps and institutional affiliations. 